\title{
Tranexamic Acid to Reduce Postpartum Hemorrhage: A MANDATE Systematic Review and Analyses of Impact on Maternal Mortality
}

\author{
Elizabeth M. McClure, $\mathrm{PhD}^{1} \quad$ Bonnie Jones, $\mathrm{MPH}^{1} \quad$ Doris J. Rouse, $\mathrm{PhD}^{1}$ Jennifer B. Griffin, $\mathrm{PhD}^{1}$ \\ Beena D. Kamath-Rayne, MD, MPH ${ }^{2}$ Allan Downs, MS $^{3}$ Robert L. Goldenberg, MD ${ }^{4}$ \\ ${ }^{1}$ Department of Social, Statistical and Environmental Health Sciences, \\ Research Triangle Institute, Durham, North Carolina \\ 2 Department of Pediatrics, Perinatal Institute, Cincinnati Children's \\ Address for correspondence Elizabeth M. McClure, PhD, Research \\ Triangle Institute, 3040 Cornwallis Road, Durham, NC 27709 \\ Hospital, Cincinnati, Ohio \\ ${ }^{3}$ Department of Research Computing Division, Research Triangle \\ Institute, Durham, North Carolina \\ ${ }^{4}$ Department of Obstetrics and Gynecology, Columbia University, \\ New York \\ Am J Perinatol 2015;32:469-474.
}

\begin{abstract}
Keywords

- postpartum hemorrhage

- tranexamic acid

- maternal mortality

- sub-Saharan Africa

Objective Postpartum hemorrhage (PPH) is a major cause of maternal mortality, with almost 300,000 cases and $\sim 72,000$ PPH deaths annually in sub-Saharan Africa. Novel prevention methods practical in community settings are required. Tranexamic acid, a drug to reduce bleeding during surgical cases including postpartum bleeding, is potentially suitable for community settings. Thus, we sought to determine the impact of tranexamic acid on PPH-related maternal mortality in sub-Saharan Africa.

Study Design We created a mathematical model to determine the impact of interventions on PPH-related maternal mortality. The model was populated with baseline birth rates and mortality estimates based on a review of current interventions for PPH in sub-Saharan Africa. Based on a systematic review of literature on tranexamic acid, we assumed $30 \%$ efficacy of tranexamic acid to reduce PPH; the model assessed prophylactic and treatment tranexamic acid use, for deliveries at homes, clinics, and hospitals.

Results With tranexamic acid only in the hospitals, less than $2 \%$ of the PPH mortality would be reduced. However, if tranexamic acid were available in the home and clinic settings for PPH prophylaxis and treatment, a nearly 30\% reduction (nearly 22,000 deaths per year) in PPH mortality is possible.

Conclusion These analyses point to the importance of preventive and treatment interventions compatible with home and clinic use, especially for sub-Saharan Africa, where the majority of births occur at home or community health clinics. Given its feasibility to be given in the home, tranexamic acid has potential to save many lives.
\end{abstract}

Postpartum hemorrhage (PPH), the leading cause of maternal mortality, is associated with up to $35 \%$ of maternal deaths worldwide, the vast majority of which occur in low-income countries, where a significant proportion of births still occur in community settings. ${ }^{1-3}$ PPH is caused by three main conditions: uterine atony, lacerations, or retained products of conception. It also may result from complications of cesarean section, ruptured uterus, disseminated received

March 15, 2014

accepted after revision

August 5, 2014

published online

October 7, 2014
Copyright $\odot 2015$ by Thieme Medical Publishers, Inc., 333 Seventh Avenue, New York, NY 10001, USA. Tel: +1(212) 584-4662.
DOI http://dx.doi.org/ 10.1055/s-0034-1390347. ISSN 0735-1631. 
intravascular coagulopathies, and other pregnancy complications. One intervention, first studied in the early 1960s, that has recently been investigated for PPH reduction is tranexamic acid (TXA), a fibrinolysis inhibitor now used routinely to decrease bleeding during surgical procedures. ${ }^{4-7}$ TXA has proven to be useful for treating a wide range of hemorrhagic conditions. The drug reduces postoperative blood loss and transfusion requirements in several types of surgery and dental procedures and appears to reduce rates of mortality and urgent surgery in patients with upper gastrointestinal hemorrhage. A recent trial found that the early administration of TXA significantly reduced mortality among trauma patients. ${ }^{6,7}$ Since this trial, TXA has been added to the WHO essential medicines list. ${ }^{8,9}$

TXA reduces menstrual blood loss and is a possible alternative to surgery in menorrhagia and is sold in the United States in an oral preparation called Lysteda. ${ }^{10,11}$ TXA is marketed in many countries, and in some countries, such as Great Britain and Sweden, because of its low complication rate, it is sold as a nonprescription medication. TXA has been shown to be stable for at least 12 weeks under a wide variety of conditions and does not require refrigeration. ${ }^{12}$ Following a single oral administration of two $650 \mathrm{mg}$ tablets of Lysteda, the recommended treatment for heavy menstrual bleeding, the peak plasma concentration occurred at $\sim 3$ hours; however, the time to reduction of bleeding after oral administration is unknown.

In obstetric trials, TXA has been used both prophylactically during labor to reduce hemorrhage with cesarean section and as a treatment for PPH, once diagnosed. ${ }^{5,13-20}$ While these studies have been conducted in a variety of settings, in most studies, a substantial decrease in blood loss was reported (several hundred $\mathrm{mL}$ ). Oral administration methods may be essential for use in community settings in low-income countries, and for its use as both a prevention and treatment of hemorrhage in these settings.

Taken together, although the numbers are small, these studies provide evidence regarding the efficacy of TXA to reduce important adverse maternal outcomes including blood loss, blood transfusion, and the need for reoperation. ${ }^{4-7,13-20}$ Given the promising results of TXA and its potential for use in low-resource settings, we sought to explore the potential value of TXA to reduce maternal mortality in sub-Saharan Africa through conducting a systematic review of TXA to reduce PPH and a mathematical model to evaluate its impact in home, clinic, and community settings in sub-Saharan Africa.

\section{Materials and Methods}

The model used for these analyses was the Maternal and Neonatal Directed Assessment of Technology (MANDATE) model. The model was populated with estimates of maternal mortality and available interventions derived from many sources (as described in detail elsewhere). ${ }^{21}$ Additionally, a systematic literature review was conducted which included all literature related to TXA in PubMed published in English since 1980, the Cochrane Library, and the World Health
Organization (WHO) database. Additional databases, including the Demographic and Household Surveys (DHS) and United Nations (UN), estimated mortality rates, rates of birth, and utilization of various interventions and mortality rates. The review was conducted using search terms "tranexamic acid," "pregnancy," "postpartum hemorrhage," "obstetric hemorrhage," and "maternal mortality." Reference papers were reviewed by at least two investigators for relevance to this analysis. A modified algorithm was applied to use estimates of efficacy from the highest quality sources as primary and, when unavailable, with support from other sources as secondary. ${ }^{22}$ Finally, the results were validated by several investigators experienced in PPH in low- and middle-income countries and incorporated into the MANDATE model for this analysis.

We restricted this assessment to sub-Saharan Africa. - Table 1 defines the key underlying variables held constant over the analysis. Based on UN data, there were $\sim 32,000,000$ births annually in sub-Saharan Africa through 2012. An estimated $50 \%$ of all deliveries in sub-Saharan Africa occurred at the home, $35 \%$ in a health clinic, and $15 \%$ in a hospital facility. ${ }^{23}$ Rates of PPH were estimated to be $\sim 11 \%$ of all pregnancies. ${ }^{24-26}$ Of the $\mathrm{PPH}, \sim 83 \%$ is estimated to be associated with uterine atony and the remainder associated with lacerations or retained products of conception. Finally, the model assumes that most women with PPH ( 90\%) will cease bleeding without intervention, but with further

Table 1 Estimated pregnancy rates and incidence and case fatality rates for postpartum hemorrhage in sub-Saharan Africa, 2012

\begin{tabular}{|c|c|}
\hline & Total \\
\hline Number of pregnancies $(N)$ & $32,951,656$ \\
\hline \multicolumn{2}{|l|}{ Site of prenatal care } \\
\hline Hospital & $5 \%$ \\
\hline Health clinic & $65 \%$ \\
\hline Home/none & $30 \%$ \\
\hline \multicolumn{2}{|l|}{ Location of delivery } \\
\hline Hospital & $15 \%$ \\
\hline Health clinic & $35 \%$ \\
\hline Home & $50 \%$ \\
\hline \multicolumn{2}{|l|}{ Estimated rates of PPH by delivery location } \\
\hline Hospital & $8 \%$ \\
\hline Health clinic & $10 \%$ \\
\hline Home & $2 \%$ \\
\hline Efficacy of TXA to treat or prevent PPH & $30 \%$ \\
\hline Postpartum hemorrhage (incidence) & $11 \%$ \\
\hline \multicolumn{2}{|l|}{ Percent of PPH by etiology } \\
\hline Uterine atony & $83 \%$ \\
\hline Lacerations & $7 \%$ \\
\hline Retained products of conception & $10 \%$ \\
\hline
\end{tabular}

Abbreviations: PPH, postpartum hemorrhage; TXA, tranexamic acid. 


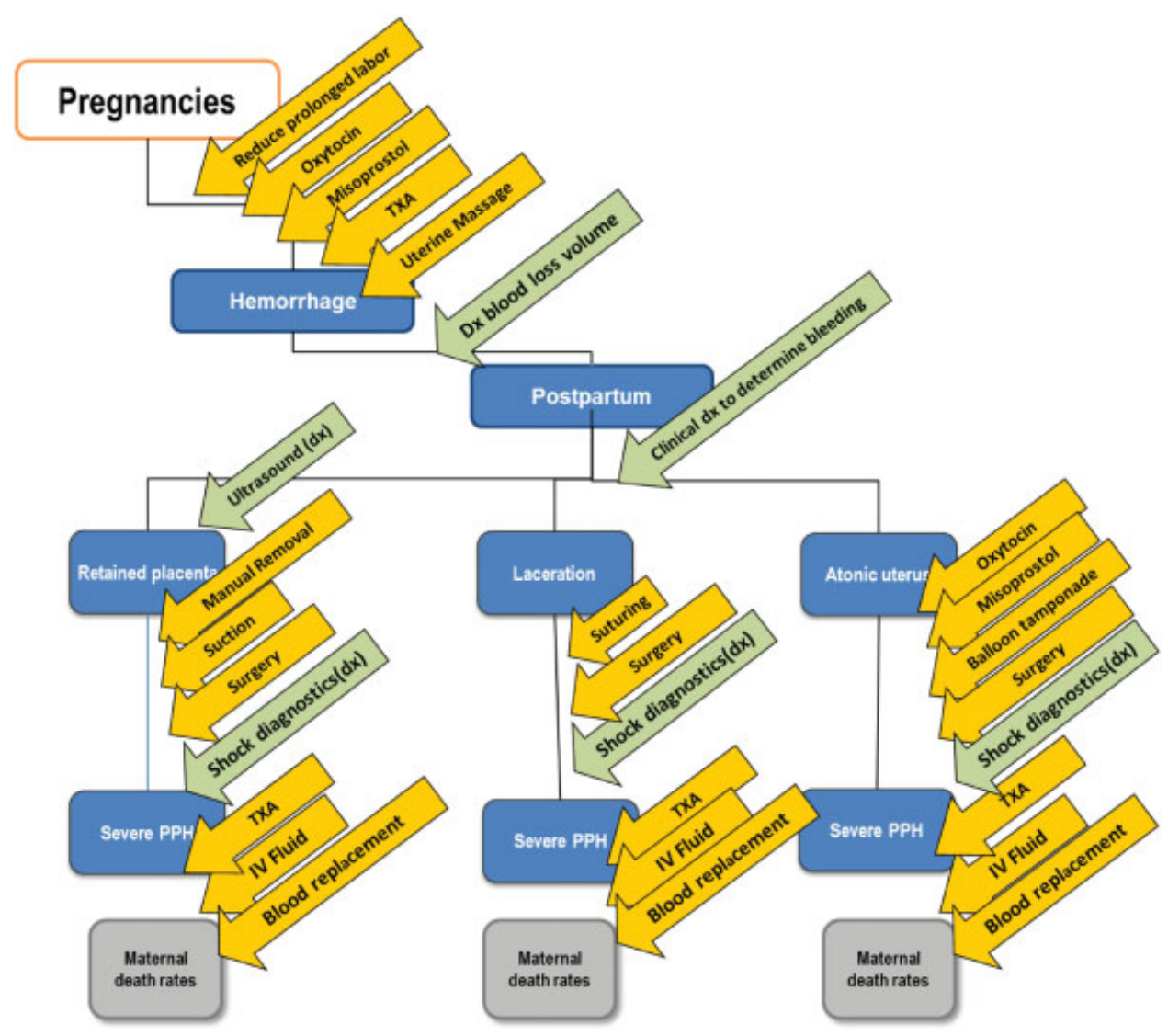

Fig. 1 MANDATE condition map for postpartum hemorrhage.

reductions in hemorrhage possible through use of existing interventions (e.g., uterine massage and oxytocics). ${ }^{27}$ The model assumes that those women who do not stop bleeding go on to have severe hemorrhage which may result in maternal death. The condition map (-Fig. 1) for prevention and treatment of PPH illustrates the possible interventions in the clinical scenario of a PPH. The penetration and utilization for each of the standard interventions described in the condition map and their associated mortality rates are referenced elsewhere (details published on the web model). ${ }^{28}$

Next, we assessed the impact of TXA in sub-Saharan Africa on PPH using an estimated efficacy of TXA based on the review. First, we examined the estimated number of cases of $\mathrm{PPH}$ and associated maternal mortality if no interventions were available for PPH. Next, the baseline status of PPH, which does not include TXA in sub-Saharan Africa, was modeled. Finally, we constructed a model to include TXA to evaluate the potential impact of TXA. We modeled TXA both as prophylactic and as a treatment for $\mathrm{PPH}$ to assess the range of potential impacts of the intervention based on the review.

\section{Results}

Regarding the efficacy of TXA and blood loss during pregnancy, our review found a total of 52 papers, of which 38 full papers were reviewed and 14 studies and meta-analyses were used to determine the estimate of the reduction in
$\mathrm{PPH}^{11-20,29-31}$ (- Fig. 2). Additional review papers were used to inform potential use and conditions for which TXA may be effective. ${ }^{15,32-40}$ In most studies, a significant decrease in blood loss was reported with TXA use. Additionally, several trials reported reduced PPH associated with TXA, with a $25 \%$

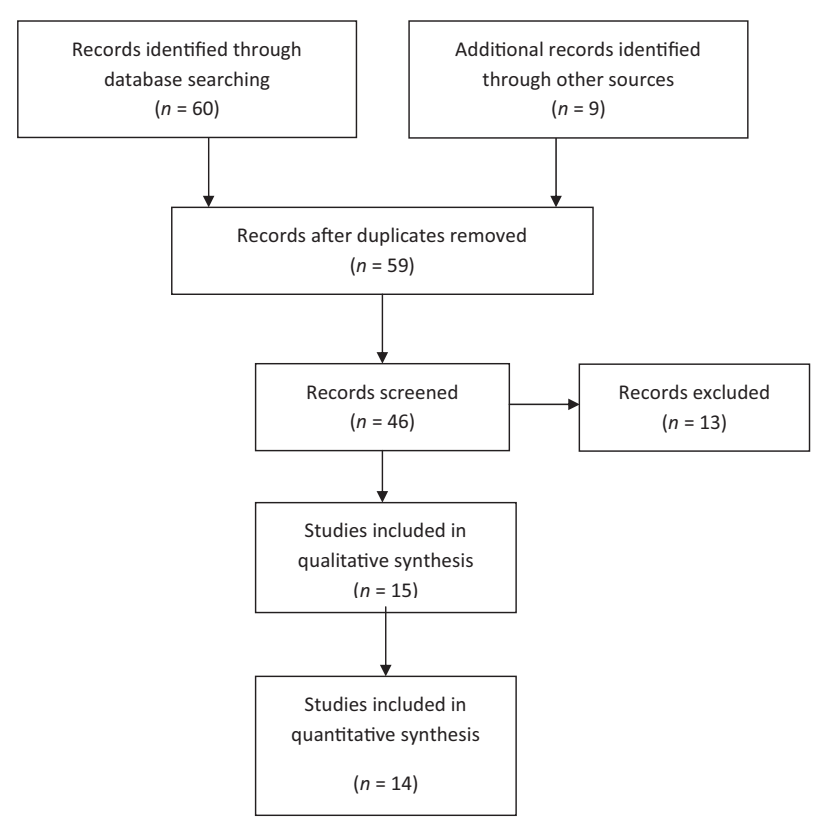

Fig. 2 Systematic review of tranexamic acid for postpartum hemorrhage. 
reduction in severe PPH reported in one trial. ${ }^{5}$ Furthermore, studies evaluating TXA use with cesarean section suggested about a one-third reduction in PPH associated with the intervention. A 2010 Cochrane review concluded that TXA decreased postpartum blood loss after vaginal and cesarean delivery based on two trials; however, it suggested that further investigation was needed to confirm these findings. ${ }^{29}$ While most PPH is due to uterine atony, the review suggested that TXA may be effective in reducing hemorrhage from all major causes of PPH, including uterine atony, lacerations, and retained products. Based on the review, we estimated that TXA used either prophylactically or as treatment of PPH could be effective in reducing $\mathrm{PPH}$ rates by $30 \%$ (range, $25-40 \%$ ).

- Table 2 summarizes the specific numbers for each scenario starting from the number of cases of $\mathrm{PPH}$, the PPH cases averted with TXA, the number of cases of severe $\mathrm{PPH}$, the number of cases of severe PPH averted with TXA, the number of deaths from $\mathrm{PPH}$, and the number of deaths averted with
TXA. The cases and deaths averted compare the baseline scenario with various TXA treatments.

The first scenario summarizes the estimated mortality if there were no interventions used to prevent, diagnose, or treat PPH. In this scenario, we estimate that there would be $\sim 95,000$ maternal deaths in sub-Saharan Africa if no interventions were available. The second scenario provides the estimated mortality and cases of severe PPH in sub-Saharan Africa in 2012, given the currently available interventions, such as uterine massage, oxytocics, transfusions, and surgical interventions. We estimate that in 2012 there were $\sim 293,000$ cases of severe PPH and 72,000 deaths from severe PPH.

The third scenario adds TXA at high (99\%) penetration and utilization to treat severe PPH only for women in hospitals, in addition to currently available interventions. In this scenario, the number of severe $\mathrm{PPH}$ cases did not change but the proportion of women who ultimately died from PPH was reduced. We estimate 1,394 maternal lives would be saved by

Table 2 Summary of scenarios evaluating impact of tranexamic acid (TXA) on postpartum hemorrhage (PPH) in sub-Saharan Africa, 2012

\begin{tabular}{|c|c|c|c|c|c|c|c|}
\hline$N$ & Scenario $^{a}$ & $\begin{array}{l}\text { Prevalence } \\
\text { of } \mathrm{PPH}\end{array}$ & $\begin{array}{l}\text { PPH cases } \\
\text { prevented } \\
\text { by TXA }\end{array}$ & $\begin{array}{l}\text { Prevalence } \\
\text { of severe } \\
\text { PPH }\end{array}$ & $\begin{array}{l}\text { Severe } \\
\text { PPH cases } \\
\text { prevented } \\
\text { by TXA }\end{array}$ & $\begin{array}{l}\text { Deaths } \\
\text { from PPH }\end{array}$ & $\begin{array}{l}\text { PPH deaths } \\
\text { prevented by } \\
\text { TXA versus } \\
\text { baseline }\end{array}$ \\
\hline 1 & No interventions for $\mathrm{PPH}$ & $3,700,703$ & NA & 370,070 & NA & 95,108 & NA \\
\hline 2 & $\begin{array}{l}\text { Baseline prevalence with current } \\
\text { interventions to reduce } \\
\text { mortality from PPH }\end{array}$ & $3,075,759$ & NA & 292,887 & NA & 71,797 & NA \\
\hline 3 & $\begin{array}{l}\text { TXA treatment (in addition to } \\
\text { current treatments) in hospitals } \\
\text { at } 99 \% \text { penetration and } \\
\text { utilization }\end{array}$ & $3,075,759$ & NA & 292,887 & NA & 70,403 & 1,394 \\
\hline 4 & $\begin{array}{l}\text { TXA treatment (in addition to } \\
\text { current treatment) in hospitals, } \\
\text { clinics, and home at } 99 \% \\
\text { penetration and utilization }\end{array}$ & $3,075,759$ & NA & 292,887 & NA & 61,840 & 9,957 \\
\hline 5 & $\begin{array}{l}\text { TXA treatment in home, clinic, } \\
\text { and hospital at } 65,85 \text {, and } 95 \% \\
\text { utilization and penetration at } \\
\text { home, clinic, and hospital }\end{array}$ & $3,075,759$ & NA & 292,887 & NA & 65,264 & 6,533 \\
\hline 6 & $\begin{array}{l}\text { TXA prophylaxis of PPH (in } \\
\text { addition to current treatments) } \\
\text { in hospitals, clinics, and at home } \\
\text { at } 99 \% \text { penetration and } \\
\text { utilization }\end{array}$ & $2,515,849$ & 559,910 & 238,732 & 54,154 & 58,346 & 13,452 \\
\hline 7 & $\begin{array}{l}\text { TXA prophylaxis and PPH } \\
\text { treatment (in addition to current } \\
\text { treatments) in hospitals, clinics, } \\
\text { and at home at high rates of } \\
\text { penetration and utilization }\end{array}$ & $2,515,849$ & 559,910 & 238,732 & 54,154 & 50,210 & 21,587 \\
\hline 8 & $\begin{array}{l}\text { TXA prophylaxis and PPH } \\
\text { treatment (with current } \\
\text { treatment) in hospitals, clinics, } \\
\text { and at home at more plausible } \\
\text { rates of penetration and } \\
\text { utilization }\end{array}$ & $2,787,238$ & 288,721 & 265,192 & 27,695 & 59,159 & 12,638 \\
\hline
\end{tabular}

${ }^{\mathrm{a}}$ For TXA, high penetration and utilization are defined as $99 \%$ for each, while more plausible rates are defined as $65 \%$ in the home, $85 \%$ in health clinic, and $95 \%$ in hospitals for penetration and utilization. 
this treatment. The fourth scenario evaluates TXA given as a treatment for severe PPH at home, clinic, and hospitals at high (99\%) penetration and utilization. Again, the number of severe PPH cases has not changed, but the number of women who ultimately die is estimated to be reduced by 9,957 from the current care model because $\sim 85 \%$ of the deliveries in subSaharan Africa occur at home or community health clinics. In the fifth scenario, we modeled TXA use at home, clinic, and hospitals, but at more plausible rates of penetration and utilization, and the number of lives saved decreased nearly by half, compared with the previous scenario.

In the next series of scenarios, we evaluated the potential use of TXA as a prophylaxis against PPH. In the sixth scenario, TXA was available for prophylaxis at high (99\%) penetration and utilization at the home, hospital, and clinic. The number of cases of severe PPH is estimated to be reduced by 54,154 to 238,732 and maternal deaths are reduced to 58,346 . We estimate that 13,452 maternal lives will be saved.

In the seventh scenario, TXA is used prophylactically as in the sixth scenario, but in addition, it was also used as a treatment at high (99\%) rates for those women who went on to develop PPH. The maternal mortality was further decreased to an estimated 50,210 deaths and 21,587 maternal lives were saved.

Finally, in the last scenario, the penetration and utilization for TXA prophylaxis was reduced to more plausible levels. The number of lives saved from TXA was reduced by nearly half from the most optimistic scenario.

\section{Comment}

One of the challenges of reducing maternal mortality associated with PPH in sub-Saharan Africa has been the low rate of hospital births and the lack of effective interventions to reduce PPH in community settings. ${ }^{3,41}$ We sought to explore the potential impact of an intervention that has effectively reduced bleeding in surgical settings and may ultimately be used in health clinics or in home deliveries. We found that with near-perfect availability and use of TXA for both prophylaxis and treatment, one could potentially reduce maternal mortality attributable to PPH by more than $30 \%$.

Reliable data to estimate mortality and the impact of interventions on mortality remain limited, especially from low-resource geographic areas in sub-Saharan Africa. Furthermore, while we used an estimated efficacy for TXA to reduce $\mathrm{PPH}(30 \%)$ which was reasonable based on available studies, the research into the efficacy of TXA for prevention of PPH and especially maternal mortality is limited. However, we used a relatively conservative estimate and ran several different scenarios to find a range of impact. Our results suggest that there is important potential for maternal mortality reduction for an intervention that could be given in home settings, especially if it were effective for different causes of PPH. In preliminary research, TXA appears to have several qualities that would make it ideal for low-resource settings-including its low cost, safety profile, and its ability to be given orally. ${ }^{9} 10$ Given that PPH remains a leading cause of mortality and the interventions available to date have not substantially reduced PPH, further evaluation of, and poten- tial investment in, interventions such as TXA appears to be warranted. Regarding safety, there is a potential for an increased risk of thrombosis since TXA is a fibrinolysis inhibitor. However, data from both obstetrical and surgical studies have not shown this to be an issue. There does appear to be a mild increase in short-lived gastrointestinal symptoms associated with TXA use.

This study has several strengths and some limitations. First, we are aware that data for some of our variables are limited and estimates are used. However, we have done extensive literature reviews of published papers and many other sources. We are also aware that maternal hemorrhage occurs in concert with other morbidities, and even if the hemorrhage is prevented or treated, death may occur due to other etiologies. The model accounts for maternal deaths due to other etiologies, and if there is no death from maternal hemorrhage, it recognizes that mortality from other etiologies can still occur. That the results are based on a computer model is both a strength and limitation. Using the model allows us to deal with hypothetical questions and to present results from several potential "what if?" scenarios. Since these scenarios are hypothetical, whether in actual practice they can be achieved is unknown. Nevertheless, the computer model presents an approximation of the deaths that may be prevented using TXA and helps to determine whether carrying out additional studies on this intervention is likely to be worthwhile. The model also allows an approximation of the potential lives saved if TXA is used only for treatment of PPH compared with potential lives saved if used prophylactically. It also points out that if TXA use is restricted to hospitals alone, few lives will be saved. Expanding TXA treatment and especially prophylaxis to clinic and home deliveries will potentially save many more lives. Therefore, randomized trials of TXA given both as a prophylactic and as treatment to reduce PPH and maternal mortality in different settings would be important.

\section{Clinical Perspective}

- Community-based interventions are needed to prevent postpartum hemorrhage, which remains a major cause of maternal mortality in developing countries.

- A systematic review was conducted and mathematical model developed to evaluate the potential impact of tranexamic acid, a drug to reduce bleeding that is potentially suitable for community settings.

- Tranexamic acid potentially will have large impact to prevent postpartum hemorrhage in developing countries.

\section{Acknowledgments}

The authors thank Dr. France Donnay for contributing to the concept development and manuscript review. This study was funded by grants from the Bill \& Melinda Gates Foundation.

\section{References}

1 Khan KS, Wojdyla D, Say L, Gülmezoglu AM, Van Look PF. WHO analysis of causes of maternal death: a systematic review. Lancet 2006;367(9516):1066-1074 
2 Beltman J, VAN DEN Akker T, VAN Lonkhuijzen L, Schmidt A, Chidakwani R, VAN Roosmalen J. Beyond maternal mortality: obstetric hemorrhage in a Malawian district. Acta Obstet Gynecol Scand 2011;90(12):1423-1427

3 Darmstadt GL, Lee AC, Cousens S, et al. 60 Million non-facility births: who can deliver in community settings to reduce intrapartum-related deaths? Int J Gynaecol Obstet 2009;107(Suppl 1): S89-S112

4 Roberts I, Ker K. Tranexamic acid for postpartum bleeding. Int J Gynaecol Obstet 2011;115(3):220-221

5 Shakur H, Elbourne D, Gülmezoglu M, et al. The WOMAN Trial (World Maternal Antifibrinolytic Trial): tranexamic acid for the treatment of postpartum haemorrhage: an international randomised, double blind placebo controlled trial. Trials 2010;11:40

6 Shakur H, Roberts I, Bautista R, et al; CRASH-2 trial collaborators. Effects of tranexamic acid on death, vascular occlusive events, and blood transfusion in trauma patients with significant haemorrhage (CRASH-2): a randomised, placebo-controlled trial. Lancet 2010;376(9734):23-32

7 Roberts I, Shakur H, Afolabi A, et al; CRASH-2 collaborators. The importance of early treatment with tranexamic acid in bleeding trauma patients: an exploratory analysis of the CRASH-2 randomised controlled trial. Lancet 2011;377(9771):1096-1101, e1-e2

8 World Health Organization. Summary of the report of the 18th meeting of the WHO Expert Committee on the Selection and Use of Essential Medicines. March 21-25, 2011; Accra, Ghana. Available at: http://www.who.int/selection_medicines/committees/expert/ 18/en/index.html

9 Guerriero C, Cairns J, Perel P, Shakur H, Roberts I; CRASH 2 trial collaborators. Cost-effectiveness analysis of administering tranexamic acid to bleeding trauma patients using evidence from the CRASH-2 trial. PLOS ONE 2011;6(5):e18987

10 Freeman EW, Lukes A, VanDrie D, Mabey RG, Gersten J, Adomako TL. A dose-response study of a novel, oral tranexamic formulation for heavy menstrual bleeding. Am J Obstet Gynecol 2011;205(4): e1-e7

11 Ducloy-Bouthors AS, Jude B, Duhamel A, et al; EXADELI Study Group. High-dose tranexamic acid reduces blood loss in postpartum haemorrhage. Crit Care 2011;15(2):R117

12 de Guzman R, Polykratis IA, Sondeen JL, Darlington DN, Cap AP, Dubick MA. Stability of tranexamic acid after 12-week storage at temperatures from $-20^{\circ} \mathrm{C}$ to $50^{\circ} \mathrm{C}$. Prehosp Emerg Care 2013;17(3): $394-400$

13 Gungorduk K, Asıcıoğlu O, Yıldııım G, Ark C, Tekirdağ AI, Besımoglu B. Can intravenous injection of tranexamic acid be used in routine practice with active management of the third stage of labor in vaginal delivery? A randomized controlled study. Am J Perinatol 2013;30(5):407-413

14 Movafegh A, Eslamian L, Dorabadi A. Effect of intravenous tranexamic acid administration on blood loss during and after cesarean delivery. Int J Gynaecol Obstet 2011;115(3):224-226

15 Peitsidis P, Kadir RA. Antifibrinolytic therapy with tranexamic acid in pregnancy and postpartum. Expert Opin Pharmacother 2011; 12(4):503-516

16 Sekhavat L, Tabatabaii A, Dalili M, Farajkhoda T, Tafti AD. Efficacy of tranexamic acid in reducing blood loss after cesarean section. J Matern Fetal Neonatal Med 2009;22(1):72-75

$17 \mathrm{Xu}$ J, Gao W, Ju Y. Tranexamic acid for the prevention of postpartum hemorrhage after cesarean section: a double-blind randomization trial. Arch Gynecol Obstet 2013;287(3):463-468

18 Shahid A, Khan A. Tranexamic acid in decreasing blood loss during and after caesarean section. J Coll Physicians Surg Pak 2013;23(7): 459-462

19 Abdel-Aleem H, Alhusaini TK, Abdel-Aleem MA, Menoufy M, Gülmezoglu AM. Effectiveness of tranexamic acid on blood loss in patients undergoing elective cesarean section: randomized clinical trial. J Matern Fetal Neonatal Med 2013;26(17):1705-1709
20 Sentürk MB, Cakmak Y, Yildiz G, Yildiz P. Tranexamic acid for cesarean section: a double-blind, placebo-controlled, randomized clinical trial. Arch Gynecol Obstet 2013;287(4):641-645

21 McClure EM, Rouse DJ, Macguire ER, et al. The MANDATE model for evaluating interventions to reduce postpartum hemorrhage. Int J Gynaecol Obstet 2013;121(1):5-9

22 Rudan I, Gibson J, Kapiriri L, et al; Child Health and Nutrition Research Initiative (CHNRI). Setting priorities in global child health research investments: assessment of principles and practice. Croat Med J 2007;48(5):595-604

23 Goudar SS, Carlo WA, McClure EM, et al. The Maternal and Newborn Health Registry Study of the Global Network for Women's and Children's Health Research. Int J Gynaecol Obstet 2012; 118(3):190-193

24 Klufio CA, Amoa AB, Kariwiga G. Primary postpartum haemorrhage: causes, aetiological risk factors, prevention and management. P N G Med J 1995;38(2):133-149

25 Dildy GA III. Postpartum hemorrhage: new management options. Clin Obstet Gynecol 2002;45(2):330-344

26 Rath WH. Postpartum hemorrhage-update on problems of definitions and diagnosis. Acta Obstet Gynecol Scand 2011;90(5): 421-428

27 Flandermeyer D, Stanton C, Armbruster D. Uterotonic use at home births in low-income countries: a literature review. Int J Gynaecol Obstet 2010;108(3):269-275

28 MANDATE model; Available at: http://mnhtech.org (Accessed November 15, 2013)

29 Novikova N, Hofmeyr GJ. Tranexamic acid for preventing postpartum haemorrhage. Cochrane Database Syst Rev 2010;(7): CD007872

30 Ferrer P, Roberts I, Sydenham E, Blackhall K, Shakur H. Antifibrinolytic agents in post partum haemorrhage: a systematic review. BMC Pregnancy Childbirth 2009;9:29

31 Gai MY, Wu LF, Su QF, Tatsumoto K. Clinical observation of blood loss reduced by tranexamic acid during and after caesarian section: a multi-center, randomized trial. Eur J Obstet Gynecol Reprod Biol 2004;112(2):154-157

32 Cook L, Roberts I; WOMAN Trial Collaborators. Post-partum haemorrhage and the WOMAN trial. Int J Epidemiol 2010;39(4): 949-950

33 As AK, Hagen P, Webb JB; AK. Tranexamic acid in the management of postpartum haemorrhage. Br J Obstet Gynaecol 1996;103(12): $1250-1251$

34 Cook L, Roberts I; WOMAN Trial Collaborators. Post-partum haemorrhage and the WOMAN trial. Int J Epidemiol 2010;39(4): 949-950

35 de Lange NM, Lancé MD, de Groot R, Beckers EA, Henskens YM Scheepers HC. Obstetric hemorrhage and coagulation: an update. Thromboelastography, thromboelastometry, and conventional coagulation tests in the diagnosis and prediction of postpartum hemorrhage. Obstet Gynecol Surv 2012;67(7):426-435

36 Onwuemene O, Green D, Keith L. Postpartum hemorrhage management in 2012: predicting the future. Int J Gynaecol Obstet 2012;119(1):3-5

37 Bonnet MP, Basso O. Prohemostatic interventions in obstetric hemorrhage. Semin Thromb Hemost 2012;38(3):259-264

38 Dunn CJ, Goa KL. Tranexamic acid: a review of its use in surgery and other indications. Drugs 1999;57(6):1005-1032

39 Sapire KE. A study of bleeding patterns with two injectable contraceptives given postpartum and the effect of two nonhormonal treatments. Adv Contracept 1991;7(4):379-387

40 Astedt B. Clinical pharmacology of tranexamic acid. Scand J Gastroenterol Suppl 1987;137:22-25

41 Kapungu CT, Mensah-Homiah J, Akosah E, et al; Ghana PPH Study Group. A community-based continuum of care model for the prevention of postpartum hemorrhage in rural Ghana. Int J Gynaecol Obstet 2013;120(2):156-159 